\title{
Nutritional rehabilitation for children with congenital heart disease with left to right shunt
}

\author{
Nehal El-Koofy, Amira M. Mahmoud, Aya M. Fattouh \\ Department of Pediatrics, Cairo University, Cairo, Egypt.E-mail: aya.fattouh@gmail.com, Aya.fattouh@kasralainy.edu.eg \\ Received: 3rd February 2017, Revised: 2nd April 2017, Accepted: 11th April 2017
}

\begin{abstract}
SUMMARY: El-Koofy N, Mahmoud AM, Fattaouh AM. Nutritional rehabilitation for children with congenital heart disease with left to right shunt. Turk J Pediatr 2017; 59: 442-451.
\end{abstract}

Children with congenital heart disease (CHD) are prone to malnutrition. We aimed to assess the nutritional status of infants with CHD and evaluate the role of nutritional counseling. A cohort study included 50 patients with acyanotic CHD causing increased pulmonary blood flow consecutively enrolled from the cardiology clinic in Cairo University Children Hospital. The patients were subjected to clinical evaluation, nutritional assessment with detailed nutritional history, anthropometric measurements and subjective global assessment (SGA) score and complete blood count, serum albumin and total protein assessment. Degree of failure to thrive (FTT) was assessed and nutritional counselling was offered to those patients; followed up for 3 months then re-evaluated. The mean age was $(8.6 \pm 4.8$ months $)$ with male: female ratio $1: 1$. The overall prevalence of malnutrition was $62 \%$. Fourteen patients had mild FTT and 17 patients had severe FTT $[47.1 \%$ with mild heart failure (HF) and $47.1 \%$ had moderate or severe HF]. All patients with moderate to severe HF had severe FTT and $80 \%$ of those with mild HF had severe FTT. Anemia was present in $96 \%$ of the patients. Patients with moderate or severe FTT had more severe degree of HF $(p<0.001)$, more complications $(\mathrm{p}<0.001)$, more frequent hospital admission $(\mathrm{p}<0.001)$ and less optimum breast feeding $(p<0.001)$. It was found that $76.5 \%$ of those with moderate to severe FTT were formula fed ( $p$ 0.002) and significantly lower rate of optimum weaning among ( $p$ 0.037). There was significant improvement in the anthropometry, the SGA and degree of FTT, level of albumin with decrease in the percent of anemia among the included patients after nutritional rehabilitation. Malnutrition represents serious problem to children with CHD. Nutritional assessment and proper counseling help to improve the nutritional status of those patients.

Key words: nutritional assessment, failure to thrive, congenital heart disease.

Congenital heart disease (CHD) among the general population is thought to be relatively similar over the world and estimated to be approximately 8 per 1,000 live births ${ }^{1}$. There are sporadic demographic studies about incidence of CHD in Egypt. It ranges between 1-2\%.2,3 Malnutrition is a constant phenomenon among children with CHD, irrespective of the nature of the cardiac defect and the presence or not of cyanosis ${ }^{4}$. Infants with CHD are prone to malnutrition for several reasons including decreased energy intake, increased energy requirements, or both. The severity of malnutrition can range from mild to severe failure to thrive. ${ }^{5}$ Growth failure has been calculated with a prevalence of $64 \%$ in CHD patients in developed countries. ${ }^{6}$ It is thought to be more severe in the developing regions reaching up to $90 \%$ in some reports, where malnutrition is common even in otherwise healthy children.5,7,8 The degree and type of malnutrition may be related to characteristics of the CHD, including presence of cyanosis, congestive heart failure (CHF), or pulmonary hypertension (PHTN). Infants with cyanosis tend to have similar alterations in both weight and length, while infants with acyanotic lesions tend to have more 
pronounced decreases in weight gain velocity as compared to length. ${ }^{9,10}$ Malnutrition in children with CHD has been associated with increased morbidity and mortality as indicated by frequent hospitalization, poor surgical outcomes, persistent impairment of somatic growth, and increased death. ${ }^{11,12}$ Appropriate nutritional care of the pediatric CHD patient first begins with thorough nutrition assessment then determination of nutrition needs. In most cases, CHD proves to be a challenge for the clinician because of the complex interplay between medical, surgical, nutritional, and social factors. ${ }^{13}$

The aim of the present study was to assess the nutritional status of group of infants with acyanotic CHD associated with increased left to right shunt and evaluate the impact of nutritional counseling for those infants on their nutritional status.

\section{Material and Methods}

This was a cohort study conducted at the cardiology clinic in Cairo University Children Hospital. Fifty patients with acyanotic CHD causing increased pulmonary blood flow aged between 4 to 21 months were enrolled in the study. Patients with associated comorbidities such as chromosomal anomalies, chronic illnesses other than CHD and those who underwent corrective intervention were excluded. Informed consent was obtained from the parents of the patients. The study was approved by the Institutional Ethics Committee.

\section{Clinical evaluation}

Patients included in the study were subjected to general examination to detect possible complications and exclude associated comorbidities. Thorough cardiac assessment was done through history taking of cardiac symptoms (shortness of breath, diaphoresis either at rest or with feeding, weak suckling and prolonged feeding times), cardiac examination (inspection, palpation and auscultation) and measurement of oxygen saturation using pulse oxymeter. Presence of complications was documented like recurrent bronchopneumonia, other acute illnesses as gastroenteritis or uncontrolled heart failure. Mothers were asked about their levels of education; those who received any degree of education even primary education were considered educated while those who did not receive any were considered non-educated.

Patients were classified according to modified Ross heart failure classification for children ${ }^{14}$ as following: a) patients with total score 0-2 had no HF, b) patients with total score 3-6 had mild HF, c) patients with total score 7-9 had moderate HF, d) patients with total score 10-12 had severe HF,

Previous detailed echocardiographic examinations performed to those patients at our hospital were reviewed to accurately record the anatomical lesions.

Full nutritional history included detailed breast feeding practice (duration, frequency and supplementation), artificial feeding (amount, concentration and frequency), weaning practice (age of start, type of food and frequency).

Full developmental history (mental and motor) was obtained.

Weight was measured in kilograms using an analog scale that had been properly calibrated (Misaki baby scale). Measurement reported to the nearest $0.1 \mathrm{~kg} .{ }^{15,16}$

Length was measured with a wooden length board with a solid headboard and a moveable footboard was used. ${ }^{16}$

Mid arm circumference (MAC) was measured in millimeters; using a flexible non-stretchable tape measure at the midpoint of the arm which lies midway between the acromion angle of the scapula and the most distant point of the olecranon process of the ulna. ${ }^{16}$

Triceps skin fold (TSF) was measured in millimeters using Slim Guide Caliper. The infant arm was firmly held extended by the mother and the skin fold was measured at the

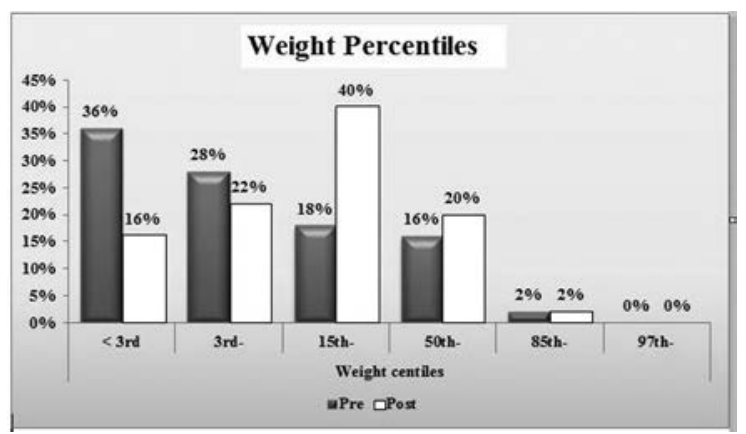

Fig. 1. Comparison between weight percentiles of the study group before and after intervention. 


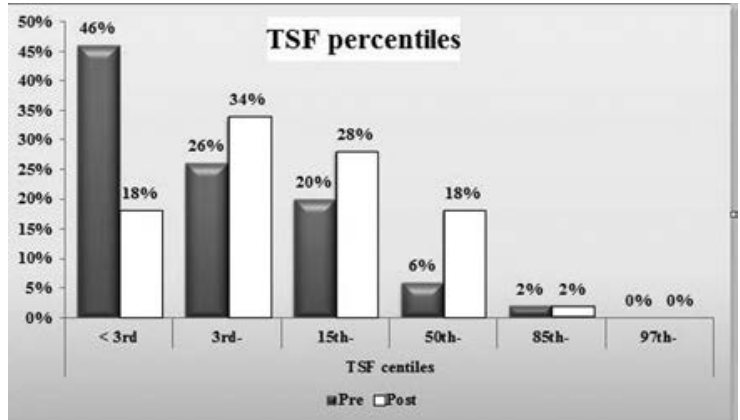

Fig. 2. Comparison between triceps skin fold (TSF) percentiles of the study group before and after intervention

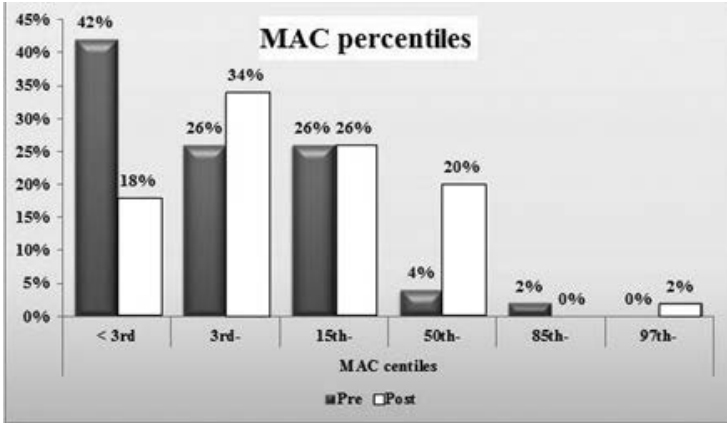

Fig. 3. Comparison between mid arm circumference (MAC) percentiles of the study group before and after intervention

Table I. Demographic and Diagnostic Data of the Study Group $(n=50)$.

\begin{tabular}{lcc}
\hline & Frequency & Percentage (\%) \\
\hline Gender & & \\
Male & 25 & 50.0 \\
Female & 25 & 50.0 \\
Age & & \\
$<1$ year & 38 & 76.0 \\
1-2 years & 12 & 24.0 \\
Diagnosis & & \\
VSD-ASD & 8 & 16.0 \\
VSD & 20 & 40.0 \\
ASD & 17 & 34.0 \\
PDA & 3 & 6.0 \\
PDA-VSD & 2 & 4.0 \\
Heart failure & 18 & 36.0 \\
Pulmonary hypertension & 24 & 48.0 \\
Grading of heart failure with the Ross score & & \\
No HF & 32 & 64.0 \\
Mild HF & 10 & 20.0 \\
Moderate HF & 4 & 8.0 \\
Severe HF & 4 & 8.0 \\
Complication & 9 & 18.0 \\
History of previous admission & 20 & 40.0 \\
Education of the mother & & 24.0 \\
Yes & 12 & 76.0 \\
No & 38 & \\
\hline VD: & & \\
\hline
\end{tabular}

VSD: ventricular septal defect, ASD: atrial septal defect, PDA: patent ductus arteriosus, HF: heart failure

midpoint of the arm, the calipers being applied immediately above the pinch. ${ }^{17}$

Calculations and correlations included:

Mid arm muscle circumference: Calculated with Medicalc mobile application, using the triceps skin fold and the mid arm circumference.
Correlation of the patient's anthropometric measures with the standard growth curves. ${ }^{18}$

Calculation of the subjective global assessment (SGA) score. ${ }^{19}$

Complete blood count was obtained from all patients and the results were evaluated using 
reference values according to age. ${ }^{20}$ Serum albumin and total protein levels of the included patients were performed and compared to reference value. ${ }^{21}$

Patients were categorized according to the degree of failure to thrive (FTT) following Waterlow criteria for classification of FTT. ${ }^{22}$

\section{Nutritional Plans}

Patient from these groups were subjected to one of the following nutritional plans:

Plan A was applied for uncomplicated cases with no or mild FTT. It included:

- Counselling about proper feeding.

- Calculation of energy requirements according to age with a range between $90-110 \mathrm{Kcal} / \mathrm{kg} /$ day) multiplied by stress factor of 1.2 to calculate extra calories for the cardiac condition.

- Protein was calculated according to age with a range between 1.1-1.6 g/kg/day. ${ }^{23}$

- Micronutrients supply in the form of: vitamin B complex syrup [including vitamin $\mathrm{B} 1$, vitamin $\mathrm{B} 2$, vitamin $\mathrm{B} 3$, vitamin $\mathrm{B} 5$, vitamin B6 (6 .3 mg/day), zinc (5 mg/ day], vitamin $\mathrm{D}$ either prophylactic dose (400 mg daily) or therapeutic dose (3000$5000 \mathrm{mg}$ daily in case of deficiency), iron either prophylactic with dose $(2 \mathrm{mg} / \mathrm{kg} /$ day) or therapeutic dose $(6 \mathrm{mg} / \mathrm{kg} /$ day $) .{ }^{24}$
Plan B was applied for uncomplicated cases with moderate to severe FTT and patients who didn't show improvement on plan A. In addition to plan $\mathrm{A}$, it included introduction of high caloric formula which gives the desired amount of calories in small volume. We used formula that gives $1 \mathrm{kcal} / \mathrm{ml}$ and other formula above the age of 1 year that gives $1.5 \mathrm{kcal} / \mathrm{ml}$. In case of unavailability of these high caloric formulas, cereals were added to the standard formula.

Plan C was applied for complicated cases and cases with severe FTT who didn't improve on plan B. It included: hospital admission for treatment of the complication, starting Ryle feeding as early as possible and training the mother on Ryle feeding. It is preferred to start from first days of admission if the patient can tolerate feeding and increase the amount gradually till reaching the full caloric requirements.

Through regular follow up visits every 2 weeks or 1 month the followings were done at each visit: weight and length measurement, counselling, assessment of plan application and if the patient needs to shift to another plan. Finally patients were reassessed after 3 months with full anthropometric measurements, the subjective global assessment score and the laboratory investigations. Comparison between these parameters before and after intervention was done.

Table II. Nutritional Assessment of the Study Group $(n=50)$.

\begin{tabular}{lcc} 
Parameter & Number & $\%$ \\
\hline Breast feeding & 37 & 74 \\
Formula feeding & 21 & 42 \\
Combined feeding & 9 & 18 \\
Weaning & 29 & 58 \\
Normal weight & 32 & 64 \\
Normal length & 48 & 96 \\
Normal weight for length & 32 & 64 \\
Normal triceps skin fold & 27 & 54 \\
Normal mid arm circumference & 29 & 58 \\
Failure to thrive & 31 & 62 \\
Normal motor development & 33 & 66 \\
Pallor & 48 & 96 \\
\hline
\end{tabular}




\section{Statistical analysis}

Data was entered on the computer using "Microsoft Office Excel Software" program (2010) for windows, then transferred to the Statistical Package of Social Science Software program, version 21 (SPSS) to be statistically analyzed. Data was summarized using, mean,standard deviation, median and percentiles for quantitative variables or frequency and percentage for qualitative ones. Comparison between groups was performed using Kruskal-Wallis test then Mann-Whitney test (pairwise comparisons) for quantitative variables while comparison for qualitative variables was performed through Chi-square or Fisher's exact test. Changes by time were measured through McNemar test for binary variables and Wilcoxon test for ordinal and quantitative ones. $\mathrm{P}$ values less than 0.05 were considered statistically significant.

\section{Results}

The present study included 50 infants with acyanotic CHD and increased pulmonary blood flow following up at the cardiology clinic in Cairo University Children Hospital. The age range was (4-21 months) and the mean age was $(8.6 \pm 4.8$ months). Table I shows the demographic and clinical data of the included patients. In this study, $56 \%$ of the patients (28 patients) were on anti-failure treatment (diuretics, captopril and/or digitalis).

The results of the nutritional assessment through history and examination are shown in Table II. The overall prevalence of failure to thrive was $62 \%$ of the studied population. This percent reached $76 \%$ on using the SGA score for assessment of the nutritional status.

We classified our patients according to the modified Ross score for heart failure into three groups, normal group $(n=32)$, group with mild HF $(n=10)$ and group of moderate and severe HF $(n=8)$. We compared the demographic, diagnostic, anthropometric and nutritional data of the three groups. We found that there was marked increase in complications ( $p<$ 0.001 ), history of previous hospital admissions

Table III. Comparison Between Normal Cases and Mild FTT and Cases with Moderate and Severe FTT as Regard Clinical and Anthropometric Data

\begin{tabular}{lccccc}
\hline & \multicolumn{4}{c}{ Failure to thrive } & \\
\cline { 2 - 4 } & \multicolumn{2}{c}{ Normal } & + Mild & Moderate & Severe \\
& $\mathrm{N}$ & $\%$ & $\mathrm{~N}$ & $\%$ & \\
\hline Grading of HF according to Ross score & & & & & \\
$\quad$ No HF & 31 & 93.9 & 1 & 5.9 & $<0.001$ \\
$\quad 2$ & 6.1 & 8 & 47.1 & \\
$\quad$ Mild HF & 0 & 0.0 & 8 & 47.1 & \\
$\quad$ Moderate + severe HF & 0 & 0.0 & 9 & 52.9 & $<0.001$ \\
History of previous hospital admission & 6 & 18.2 & 14 & 82.4 & $<0.001$ \\
Optimum breast feeding & 26 & 78.8 & 2 & 11.8 & $<0.001$ \\
Optimum weaning & 7 & 21.2 & 0 & 0.0 & 0.080 \\
Episodes of illness & 4 & 12.1 & 10 & 58.8 & 0.001 \\
Anemia & 33 & 100.0 & 15 & 88.2 & 0.111 \\
$\quad$ Mild & 13 & 39.4 & 3 & 20.0 & 0.322 \\
$\quad$ Moderate & 20 & 60.6 & 12 & 80.0 & \\
Education of the mother & 10 & 30.3 & 2 & 11.8 & 0.181 \\
Compliance for the plan & 31 & 93.9 & 9 & 52.9 & 0.001 \\
Anemia (after intervention) & 25 & 75.8 & 15 & 88.2 & 0.461 \\
Anemia degree (after intervention) & & & & & \\
$\quad$ Mild & 21 & 84.0 & 8 & 53.3 & 0.065 \\
$\quad$ Moderate & 4 & 16.0 & 7 & 46.7 & \\
\hline
\end{tabular}

HF: heart failure, FTT: failure to thrive 
$(\mathrm{p}<0.001)$, episodes of acute illnesses ( $\mathrm{p}<$ $0.001)$ and degree of FTT $(p<0.001)$ for the group with severe heart failure. None of the patients with moderate to severe heart failure had normal weight for age, only 30\% of the patients with moderate heart failure had normal weight for age and $90 \%$ of those without heart failure had normal weight for age. All patients with moderate to severe heart failure had severe FTT, $80 \%$ of those with mild heart failure had severe FTT and only one case without heart failure had severe FTT. Anemia was present in $96 \%$ of the patients (the two cases who did not have anemia as they received blood transfusions while they were admitted to the hospital).

The patients were classified according to the degree of FTT into three groups; normal cases $(n=19)$, cases with mild FTT $(n=14)$ and third group cases with moderate and severe FTT $(n=17)$. Patients with severe FTT had either mild $(47.1 \%)$ or moderate to severe heart failure $(47.1 \%)$ and only one case $(5.9 \%)$ had no heart failure $(\mathrm{p}<0.001)$. For those with mild FTT, only two patients had mild heart failure $(14.3 \%)$ and the remaining patients had no heart failure $(85.7 \%)$. There were statistically significant differences between the groups regarding the occurrence of complications $(0.0 \%, 0.0 \%$, and $52.9 \%$, respectively; p $<0.001)$ and history of previous admission $(10.5 \%, 28.6 \%$, and $82.4 \%$, respectively; $\mathrm{p}$ $<0.001)$. It was found that $76.5 \%$ of those with moderate to severe FTT were formula fed $(21.1 \%, 28.6 \%$, and $76.5 \%$, respectively; p 0.002). Weaning was significantly lower among patients with moderate to severe FTT compared to those without heart failure or with mild heart failure $(41.2 \%, 52.6 \%$, and $85.7 \%$, respectively; p 0.037).

Comparison between those with mild or no FTT and those with moderate and severe FTT showed that the second group had more severe degree of HF $(\mathrm{p}<0.001)$, more complications, $(\mathrm{p}<0.001)$, more frequent hospital admission $(\mathrm{p}<0.001)$, and less optimum breast feeding, $(\mathrm{p}<0.001)$, as shown in Table III. But we didn't find statistically significant difference between the three groups (without FTT, mild FTT and moderate to severe FTT) as regard the presence or the degree of anemia. The groups were comparable for the type of cardiac defects.

Patients were categorized and received one of the three plans: plan A for 34 patients, plan $\mathrm{B}$ for 8 patients and plan $\mathrm{C}$ for another 8 patients. We compared the patients before and after the application of the medical nutritional therapy regarding the anthropometric data, nutritional assessment and presence of anemia as illustrated in Tables IV and V. The physical growth parameters were blotted on the growth centiles for each patient and the results are shown in Figures $(1,2,3)$ with comparison after nutritional intervention. There was significant improvement in the anthropometry, the presence of anemia and its degree and the level of albumin. There was also marked improvement in the SGA and degree of FTT of the included patients.

During the period of the follow up we found that 40 mothers $(80.0 \%)$ were compliant with the plan. During the period of follow up 14 patients $(28.0 \%)$ had episodes of illness. Ten

Table IV. Mean of Anthropometric and Laboratory Data Before and After Intervention.

\begin{tabular}{lrrr}
\hline & $\begin{array}{c}\text { Before } \\
\text { (mean } \pm \text { SD) }\end{array}$ & $\begin{array}{c}\text { After } \\
\text { (mean } \pm \text { SD) }\end{array}$ & P \\
\hline Weight $(\mathrm{kg})$ & $6.8 \pm 1.7$ & $8.1 \pm 1.8$ & $<0.001$ \\
Length $(\mathrm{cm})$ & $68.3 \pm 6.8$ & $72.4 \pm 6.1$ & $<0.001$ \\
TSF $(\mathrm{mm})$ & $6.4 \pm 1.7$ & $6.8 \pm 1.5$ & $<0.001$ \\
MAC $(\mathrm{cm})$ & $12.2 \pm 1.6$ & $13.2 \pm 1.6$ & $<0.001$ \\
MAMC $(\mathrm{cm})$ & $10.2 \pm 1.2$ & $11.1 \pm 1.3$ & $<0.001$ \\
Hemoglobin $(\mathrm{g} / \mathrm{dl})$ & $9.7 \pm 0.7$ & $10.3 \pm 0.7$ & $<0.001$ \\
Albumin $(\mathrm{g} / \mathrm{dl})$ & $4.2 \pm 0.3$ & $4.2 \pm 0.5$ & 0.597 \\
Total protein $(\mathrm{g} / \mathrm{dl})$ & $6.6 \pm 0.3$ & $6.9 \pm 0.5$ & $<0.001$ \\
\hline
\end{tabular}

TSF: triceps skin fold, MAC: mid arm circumference, MAMC: mid arm muscle circumference MAMC: mid arm muscle circumference 
patients were on plan A initially and were shifted to plan B as they were not gaining enough weight. Another two patients were shifted from plan B to plan C.

\section{Discussion}

The overall prevalence of malnutrition (according to Waterlow criteria for failure to thrive) was found to be present in $62 \%$ of the studied population. This percent reached $76 \%$ on using the SGA score for assessment of the nutritional status. Previous studies have reported different rates of malnutrition among the patients with CHD which ranged from $15 \%$ up to $90.4 \% .^{8,25-28}$ It was comparatively very low from developed countries like France, where Blasquez et al. ${ }^{25}$ reported a percent of $15 \%$. While in South India, Vaidyanathan et al. ${ }^{26}$ reported a high prevalence of underweight $(59.0 \%)$ in children with CHD. In Nigeria, Okoromah et al. ${ }^{27}$ conducted a case-control observational study to evaluate prevalence and predictors of malnutrition in children with uncorrected symptomatic CHD describing a prevalence of $90.4 \%$. In Turkey, Tokel et al. ${ }^{28}$ described a prevalence of $85 \%$ while Hassan et al. ${ }^{8}$ in Egypt reported a rate of $84 \%$. This wide range of variation is attributed first to the different study population whether cyanotic, acyanotic or both types of CHD. The second cause of variation maybe because some of these studies included hospitalized children or those with delayed intervention. The high prevalence rate in our study could be attributed to the fact that our center is the largest tertiary pediatric cardiac center in Egypt receiving the most difficult and complicated cases with even delayed surgical interventions. Patients with a delay in surgical repair are more prone to malnutrition and growth delay than others ${ }^{13}$. Unfortunately, the surgeons in our center prefer to go for total repair for those patients with VSD and common atrioventricular (AV) canal with body weight over $6 \mathrm{~kg}$ which is in most of those cases very difficult to achieve due to their poor nutritional status which makes nutritional support for those patients essential to go for their surgical correction. The mechanism for growth retardation in infants and children with CHD is multifactorial including inadequate intake, increased oxygen consumption, increased mean total daily energy expenditure, impaired absorption secondary to chronic venous congestion of the bowel, and inefficient utilization of nutrients by the tissues. ${ }^{26}$ Prolonged and recurrent hospital stay is an important contributing factor to the deterioration of the nutritional status. ${ }^{29}$ Drugs used for controlling heart failure can also affect the nutritional status through different mechanisms. ${ }^{13}$ In this study, $56 \%$ of the patients ( 28 patients) were on anti-failure treatment which was a contributing factor for malnutrition.

Table V. Comparison of the Nutritional Assessment Before and After Intervention.

\begin{tabular}{|c|c|c|c|c|c|}
\hline \multirow{2}{*}{ Variable } & \multicolumn{2}{|c|}{ Before } & \multicolumn{2}{|c|}{ After } & \multirow[t]{2}{*}{$\mathrm{P}$} \\
\hline & $\mathrm{N}$ & $\%$ & $\mathrm{~N}$ & $\%$ & \\
\hline \multicolumn{6}{|l|}{ FTT } \\
\hline Normal & 19 & 38.0 & 33 & 66.0 & \multirow{4}{*}{$<0.001$} \\
\hline Mild & 14 & 28.0 & 12 & 24.0 & \\
\hline Moderate & 7 & 14.0 & 3 & 6.0 & \\
\hline Severe & 10 & 20.0 & 2 & 4.0 & \\
\hline \multicolumn{6}{|l|}{ SGA } \\
\hline Normal & 24 & 48.0 & 40 & 80.0 & \multirow{3}{*}{$<0.001$} \\
\hline Moderate & 16 & 32.0 & 7 & 14.0 & \\
\hline Severe & 10 & 20.0 & 3 & 6.0 & \\
\hline Anemia & 48 & 96.0 & 40 & 80.0 & 0.008 \\
\hline \multicolumn{6}{|l|}{ Anemia degree } \\
\hline Mild & 16 & 33.3 & 29 & 72.5 & \multirow{2}{*}{$<0.001$} \\
\hline Moderate and severe & 32 & 66.7 & 11 & 27.5 & \\
\hline
\end{tabular}

TSF: triceps skin fold, MAC: mid arm circumference, FTT: failure to thrive, SGA: subjective global assessment score 
We found that malnutrition among our patients with moderate and severe FTT was associated with more severe heart failure, higher incidence of complications and more frequent hospital admission. This was previously reported by other investigators. ${ }^{30}$ It could be explained by the fact that patients with severe FTT have low immunity and more liable to infection or that the severity of FTT is a result of the complications. Congestive heart failure and repeated chest infection are the primary concern in infants with acyanotic lesions and so feeding difficulty is common and is often associated with tachypnea, sweating and subcostal retraction. ${ }^{31}$ Micronutrient deficiencies and infectious diseases often coexist and exhibit complex interactions leading to the vicious cycle of malnutrition and infections particularly in preschool children. ${ }^{32}$

Anemia was encountered in $96 \%$ of our patients which is higher than what was reported by other investigators. ${ }^{27,33}$ Comparison between the different groups of FTT revealed no difference in the percentage of anemia among those patients. This can be explained by the fact that Egyptian children have high prevalence of iron deficiency anemia. ${ }^{34-36}$

Detailed nutritional history for our patients revealed that severe FTT was more common with formula feeding than those who were breast fed and that most normal patients were breast fed. This supports the fact that breast feeding has protective and immune function which prevents infections and complications that leads to FTT. It is difficult to answer the question whether to breast or bottle feed an infant with CHD. Although breast feeding is optimum for immunity and nutrition and less stressful for the infant, bottle feeding may be indicated to introduce excess calories. Breastfeeding has been emphasized to significantly lower hospitalization secondary to diarrheal and lower respiratory tract infections in the first 8 months after birth in healthy infants. ${ }^{37}$ Delayed weaning was noticed in $18 \%$ of the studied population maybe due to recurrent hospitalization with more easy use of bottle feeding and absence of proper nutritional counseling.

In order to try to improve the nutritional status for our patients, they received medical nutritional therapy for three months and were reassessed. The caloric intake was increased without increasing the volume in addition to micronutrients supplementation. We found significant improvement in weight, MAC and TSF while the length showed no significant change. Anemia as well has decreased from $96 \%$ of cases to $80 \%$ after nutritional counseling with increase in the mean level of hemoglobin. Dietary intervention including nutritional analysis and counseling is thought to help increasing the intake of calories and consecutively increased weight. Parental education from a dietitian plays an important role in optimizing feeding of those children. We found that nutritional counseling and spending enough time to explain the plan for the mothers had positive effect on their compliance and outcome of cases. Nutritional assessment and management can potentially optimize the nutrition status in children with CHD during the perioperative period. ${ }^{38}$ Unfortunately, mothers of the patients with moderate or severe heart failure were less compliant than mothers of patients with mild or no heart failure which could be due to difficulties in the management plan for these patients such as Ryle feeding. This means that those mothers require more education and frequent counseling.

To the best of our knowledge, most of the studies about nutritional rehabilitation in children with CHD were retrospective studies. But the current study being prospective gives us the opportunity to modulate the nutritional plans and shift the patients between them. Nutritional rehabilitation in those patients should be a continuous process with close monitoring and follow up.

In conclusion, malnutrition and failure to thrive represent serious problems to children with acyanotic CHD. Nutritional assessment and proper counseling help to improve the nutritional status of those patients. We need to conduct more future studies including more patients to put our own nutritional guidelines which should be part of the medical care provided for children with CHD.

\section{REFERENCES}

1. Van der Linde D, Konings EE, Slager MA, et al. Birth prevalence of congenital heart disease worldwide: A systematic review and meta-analysis. J Am Coll Cardiol 2011; 58: 2241-2247. 
2. Salem SA, El-Feky OA. Epidemiological study of congenital heart diseases among children attending outpatient clinics of Benha University Hospital. Egypt J Community Med 2011; 28: 69-87.

3. Bassili A, Mokhtar SA, Dabous NI, et al. Risk factors for congenital heart diseases in Alexandria, Egypt. Eur J Epidemiol 2000; 16: 805-814.

4. Mitchell M, Logan RW, Pollock JCS, Jamieson MPG. Nutritional status of children with congenital heart disease. Br Heart J 1995; 73: 277-283.

5. Varan B, Tokel K, Yilmaz G. Malnutrition and growth failure in cyanotic and acyanotic congenital heart disease with and without pulmonary hypertension. Arch Dis Child 1999, 81: 49-52.

6. Cameron JW, Rosenthal A, Olson AD. Malnutrition in hospitalized children with congenital heart disease. Arch Pediatr Adolesc Med 1995; 149: 1098-1102.

7. Thompson-Chagoyan OC, Reyes-Tsubaki N, Rabiela Barrios OL, Buendia-Hernandez A, Miranda Chavez I, Carrasco Quintero R. The nutritional status of the child with congenital cardiopathy. Arch Inst Cardiol Mex 1998; 68: 119-123.

8. Hassan BA, Albanna EA, Morsy SM, et al. Nutritional status in children with un-operated congenital heart disease: An Egyptian center experience. Front Pediatr 2015; 15: 1-5.

9. Norris MK, Hill CS. Nutritional issues in infants and children with congenital heart disease. Crit Care Nurs Clin North Am 1994; 6: 153-163.

10. Leitch CA. Growth, nutrition and energy expenditure in pediatric heart failure. Prog Pediatr Cardiol 2000; 11: 195-202.

11. Forchielli ML, McColl R, Walker WA, Lo C. Children with congenital heart disease: A nutrition challenge. Nutr Rev 1994; 52: 348-353.

12. FreemanL M, Roubenoff R. The nutrition implications of cardiac cachexia. Nutr Rev 1994; 52: 340-347.

13. Roman B. Nourishing little hearts: Nutritional implications for congenital heart defects. Pract Gastroenterol 2011; 35: 11-34.

14. Ross RD. The Ross classification for heart failure in children after 25 years: A review and an age-stratified revision. Pediatr Cardiol 2012; 33: 1295-1300.

15. Flaherty-Hewitt M. Nutrition and Growth Measurement Technique. Available at: http://emedicine.medscape. com/article/1948024-technique. Updated on September 19, 2012 (Accessed September, 2015).

16. Cape Town Metropole Pediatric Interest Group. Anthropometry guideline, 2009

17. Paul AA, Cole TJ, Ahmed EA and Whitehead RG. The need for revised standards for skinfold thickness in infancy. Arch Dis Child 1998; 78: 354-358.

18. Rojratsirikul C, Sangkhathat S, Patrapinyokul S. Application of subjective global assessment as a screening tool for malnutrition in pediatric surgical patients. J Med Assoc Thai 2004; 9: 939-946.
19. WHO, UNICEF, UNU. Iron deficiency anemia: assessment, prevention and control, a guide for programme managers. Geneva, World Health Organization, 2001. Available at: http://www.who.int/ nutrition/publications/micronutrients/anaemia_iron deficiency/WHO_NHD_01.3/en/index.html (Accessed June, 2016).

20. McPherson RA, Pincus MR. Henry's Clinical Diagnosis and Management by Laboratory Methods (22nd ed). Saunders, 2011.

21. Waterlow JC. Classification and definition of proteincalorie malnutrition. BMJ 1972; 3: 566-569.

22. Cape Town Metropole Paediatric Working Group: Clinical Guidelines CHD, 2009

23. Morley JE. Overview of under nutrition. Available at: http://www.msdkmanuals.com/professional/ nutritional-disorders/undernutrition/overview-ofundernutrition. (Accessed September, 2015).

24. Blasquez A, Clouzeau H, Fayon M, Mouton JB, Thambo JB, Enaud R, Lamireau T. Evaluation of nutritional status and support in children with congenital heart disease. Eur J Clin Nutr 2016; 70: 528-531.

25. Vaidyanathan B, Kumar RK. What determines nutritional recovery in malnourished children after correction of congenital heart defects? Pediatrics 2009; 124: e294-e299.

26. Okoromah CA, Ekure EN, Lesi FE, Okunowo WO, Tijani BO, Okeiyi JC. Prevalence, profile and predictors of malnutrition in children with congenital heart defects: A case-control observational study. Arch Dis Child 2011; 96: 354-360.

27. Tokel K, Azak E, Ayabakan C, Varan B, Așlamaci SA, Mercan S. Somatic growth after corrective surgery for congenital heart disease. Turk J Pediatr 2010; 52: 58-67.

28. Mansfield AN. Nutrition support protocols and early feeding in the intensive care unit (Doctoral dissertation, Bowling Green State University), 2008.

29. Ross RD, Bollinger RO, Pinsky WW. Grading the severity of congestive heart failure in infants. Pediatr Cardiol 1992; 13:72-75

30. Anderson RH, Baker EJ, Rigby ML, Shinebourne EA Tynan M. Pediatric Cardiology (2nd ed). Philadelphia, Churchill Livingstone, 2002.

31. Bhaskaram P. Micronutrient malnutrition, infection, and immunity: An overview. Nutr Rev 2002; 60: S40-S45.

32. Drossos C, Thanapoulos B, Papadimitrou T, et al. Incidence of anaemia in congenital heart diseases. Pediatr Med Chir 1981; 3: 309-312.

33. Tawfik AA, Hanna ET, Abdel-Maksoud AM. Anemia and iron deficiency anemia in Egypt. IOSR-PHR 2015; 5: 30-34.

34. UNICEF. Children in Egypt: A statistical digest, June 2015. UNICEF Egypt, Cairo, Egypt. 2015.

35. Austin AM, Fawzi W, Hill AG. Anaemia among Egyptian Children between 2000 and 2005: Trends and predictors. Matern Child Nutr 2012; 8: 522-532. 
36. Quigley MA, Kelly YJ, Sacker A. Breastfeeding and hospitalization for diarrheal and respiratory infection in the United Kingdom Millennium Cohort Study. Pediatrics 2007; 119: e837-e842.
37. Wong JJ, Cheifetz IM, Ong C, Nakao M, Lee JH Nutrition support for children undergoing congenital heart surgeries: A narrative review. World J Pediatr Congenit Heart Surg 2015; 6: 443-454. 